\title{
(बR \\ Just Get Headache... Isolated Transverse Sinus Venous Thrombosis
}

\author{
Sadece Başım Ağrıyor... İole Transvers Sinüs Ven Trombozu
}

\author{
Ayhan Özhasenekler ${ }^{1}$, Hasan Mansur Durgun', Ömer Kaçmaz' , İbrahim Tunç ${ }^{1}$, Eşref AkıI², Hakan Önder ${ }^{3}$ \\ 'Department of Emergency, Faculty of Medicine, Dicle University, Diyarbakır, Turkey \\ 2Department of Neurology, Faculty of Medicine, Dicle University, Diyarbakır, Turkey \\ ${ }^{3}$ Department of Radiology, Faculty of Medicine, Dicle University, Diyarbakır, Turkey
}

\section{ABSTRACT}

Cerebral venous thrombosis is a rare condition than arterial oclusive disease of brain. While sagittal and cavernous sinus thrombosis are frequently seen, transverse sinus thrombosis is rare. Clinically, headache is the most common and the initial symptom. The first diagnostic tool of cerebral venous thrombosis is non-contrast brain tomography. Non-contrast brain tomography, one of the imaging methods commonly used in patients with a headache in the emergency room, should be evaluated well.

Keywords: Headache, transverse sinus thrombosis, brain tomography

Received: 19.12.2011 Accepted: 12.02.2012

\section{ÖZET}

Serebral ven trombozu beynin arteryel tıkayıcı hastalıklarına oranla daha nadir görülen bir durumdur. Sagittal ve kavernöz sinüs trombozu sık görülürken transvers sinüs trombozu daha nadirdir. Klinik olarak baş ağrısı, en yaygın ve başlangıç semptomudur. Serebral ven trombozlarının ilk tanı aracı, kontrastsız beyin bilgisayarlı tomografisidir. Acilde, baş ağrısı ile başvuran hastaların, sık kullanılan görüntüleme yöntemlerinden kontrastsız beyin tomografilerinin iyi değerlendirilmesi gerekir.

Anahtar Kelimeler: Baş ağrısı, transvers sinüs trombozu, beyin tomografi

Geliş Tarihi: 19.12.2011 Kabul Tarihi: 12.02.2012

\section{Giriş}

Serebral ven trombozları, acil servislere baş ağrısı şikayeti ile başvuran hastaların ön tanılarından biri olarak düşünülmelidir. Beyin arteryel tıkayıı hastalıklarına oranla daha nadir görülen bir durumdur. Hastaların tek başvuru şikayeti baş ağıısı olabileceği gibi çeşitli nörolojik semptomlarla da başvurabilirler. Serebral ven trombozlarının ilk tanı aracı kontrastsız bilgisayarlı beyin tomografi (BBT)'dir. Bu makalede acil servisimize sadece baş ağrısı şikayetiyle başvuran, nörolojik muayenesi normal olan ve BBT kesitlerinde transvers sinüs trombozu saptanan bir olgu sunuldu.

\section{Olgu Sunumu}

Kırk yaşında erkek hasta iki gündür şiddeti giderek artan baş ağrısı nedeniyle kliniğimize başvurdu. Ağrısının en çok ense bölgesinde olduğunu ve daha önce hiç böyle bir baş ağrısı çekmediğini söyledi. Öyküsünde ilaç kullanımı yoktu. Fizik bakısında genel durumu orta, şuur açık, kan basıncı 115/75 mmHg, nabız 84/dk, vücut ısısı: $37^{\circ} \mathrm{C}$ idi. Pupiller izokorik, ışık refleksi +/+, ense sertliği yok, kranial sinir muayeneleri ve diğer nörolojik muayeneleri normal olarak değerlendirildi. Laboratuvar bulgularında; beyaz küre: 11,7 K/UL idi. Hemoglobin, hematokrit, trombosit, böbrek ve karaciğer fonksiyon testleri, elektrolitleri ve kanama profili normal aralıklarda idi. Hastaya bilgisayarlı beyin tomografisi (BBT) çekildi (Resim 1). Sağ transvers sinüs dansitesi artmış olup, içerisinde dolum defektini düşündüren hipodens görünüm, ayrıca sağ temporo-oksipital bölgede öncelikle transvers sinüs ven trombozunu düşündüren sulkuslarda silinmeye yol açan hiperdens görünüm izlendi. Hasta Nöroloji Yoğun Bakıma yatııılı. İntravenöz (IV) antibiyotik, acetyl salicylic acid 100 mg tablet, düşük molekül ağırlıklı heparin (DMAH), nimodipin tablet ile birlikte semptomatik destek tedavisi başlandı. Yatışından yaklaşık 8 saat sonra ani hipertansif atak sonrası 


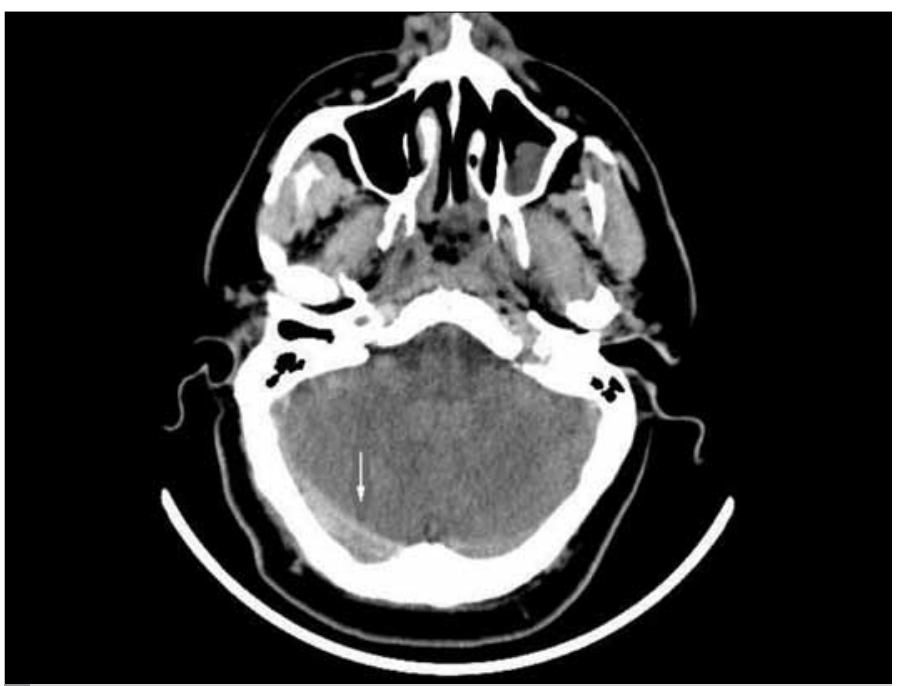

Resim 1. Hastanın transvers sinüs trombozunu gösteren beyin BT kesiti

kardiyopulmoner arrest gelişti. Yaklaşık yirmi dakika süren kardiyopulmoner resüsitasyon sonrası kardiyak ritmi sinüs taşikardisi idi. Resüsitasyon sonrası spontan solunumu olmayan hastanın takibine mekanik ventilatör desteği altında devam edildi. Glasgow koma skalası (GKS) 3 idi. Hastaya mevcut durumundan dolayı radyolojik görüntüleme yapılamadı. Tanısal amaçıı lomber ponksiyon yapıldı. Lomber ponksiyon hemorajikti. Hastada ani hipertansif atak sonrası subaraknoid kanama gelişmiş olabileceği düşünüldü. Cerrahi girişim düşünülmedi. Takibinin 3. gününde eks oldu.

\section{Tartışma}

Serebral ven trombozu beynin arteryel tıkayıcı hastalıklarına oranla daha nadir görülen bir durumdur. Sagittal ve kavernöz sinüs trombozu sık görülürken transvers sinüs trombozu daha nadirdir. Hastalar kafa içi basınç artışına işaret eden baş ağrısı, bulantı, kusma ve papilla ödemi, fokal veya jeneralize epileptik nöbetler ve fokal nörolojik defisitler ile başvurabilirler (1). Bir çok seride baş ağrısının, en yaygın ve başlangıç semptomu olduğu bildirilmiştir (2). Gosk-Bierska ve ark.'larının (3) yaptığı bir çalışmada en yaygın semptom olarak baş ağrısı \%87, en yaygın bulgu olarak papil ödemi \%55 oranında bulunmuştur. Aynı zamanda hastaların \%25'inin nörolojik muayeneleri normal olarak değerlendirilmiştir. Bizim hastamızın da başvuru şikayeti sadece baş ağrısı idi. Göz dibi muayenesinde papil ödemine rastlanmadı ve nörolojik muayenesi normal idi.

Serebral ven trombozları gebelik, laktasyon dönemi ve oral kontraseptif kullanımından dolayı 20-35 yaş arası bayanlarda daha sık görülür (4). Hastamızın erkek olmasından dolayı trombofili gibi diğer risk faktörleri açısından da herhangi bir risk faktörüne rastlamadık.

Serebral ven trombozlarının ilk tanı aracı kontrastsız BBT'dir. Başvuru anındaki BBT normal olabileceği gibi BBT'de; sinüs dansitesinde artış, içerisinde dolum defektine bağlı hipodens görünüm ve çevre dokularda ödem görülebilir. Hastamızın BBT' sinde; sağ transvers sinüs dansitesi artmış olup, içerisinde dolum defektini düşündüren hipodens görünüm, ayrıca sağ temporo-oksipital bölgede öncelikle sinüs ven trombozunu düşündüren sulkuslarda silinmeye yol açan hiperdens görünüm izlendi. Azın ve ark'larının (5) yaptığı 61 hastalık tüm serebral ven trombozlu hastaları kapsayan geriye dönük bir çalışmada, başvuru anında çekilen BBT \%30,9 oranında normal bulunmuştur. Tanıyı doğrulamak için BT anjio, magnetik rezonans (MR) veya MR venografinin kullanılabileceği bildirilmiştir.

Serebral ven trombozlarının tedavisi etyolojiye yönelik, semptomatik ve antitrombotik tedavi olarak üç basamaklıdır. Semptomatik tedaviler; antiepileptik tedaviyi, artmış kafa içi basıncını düşürmeye yönelik kortikosteroid, asetazolamid ve gerektiğinde boşaltıcı lomber ponksiyon uygulamasını, enfeksiyon odağı varlığında antibiyoterapiyi kapsar (1). Biz de hastamıza profilaktik IV antibiyotik, kafa içi basınç artışını önlemek ve iskemik hasarı önlemek amaçlı nimodipin tablet başladık.

Antitrombotik tedavi tartışmalıdır. İyi seyirli özellikle izole kafa içi basıncı artışı ile giden durumlarda veya hemorajik venöz infarktlı olgularda uygulanmaması gerektiğini öne sürenler olsa da; klasik yaklaşım, hemorajik venöz infarkt varlığında bile etkin dozda heparin veya düşük molekül ağılıklı heparinlerle tedaviye başlamak, altta yatan bir kalıtsal trombofili olmadıkça tedaviye 3-6 ay boyunca oral antikoagülan tedaviyle (varfarin) devam etmektir (1). Biz de hastamıza acetyl salicylic acid ve DMAH başladık.

Serebral ven trombozlarının büyük kısmının prognozları, zengin anastomoz ve kollateral dolaşımın varlığından dolayı iyi seyirlidir. Yaş, başlangıçta komanın varlığı, fokal bulguların olması, derin ven sisteminin tutulması ve özellikle septik trombozlar, prognozu kötüleştiren faktörlerdir (1). Canhao ve ark'larının (6) yaptığı bir çalışmada ölüme neden olan ana faktörler olarak; nöbet varlığı, baskılanmış şuur, derin serebral venöz sistemlerin tutulması, hemoraji varlığı ve posterior fossa lezyonlarının varlığı bildirilmiştir. Özellikle posterior fossa kanamalarında transtentorial herniasyon ani kardiyopulmoner arrest nedeni olarak belirtilmiştir. Biz de hastamızda, kardiyopulmoner arrestin nedeni olarak; ani hipertansif atak sonrası subaraknoid kanama ve buna bağlı transtentorial herniasyon gelişmiş olabileceğini düşünüyoruz. Ancak hastamızın resüsitasyon sonrası GKS'nin 3 olması, verilen tedaviye rağmen nörolojik durumunda bir gelişme olmaması üzerine tanısal amaçıı radyolojik görüntüleme uygulayamadık.

\section{Sonuç}

Baş ağrısı ile acile başvuran hastalarda, iskemik veya hemorajik infarktın yanında serebral ven trombozlarının da akılda tutulması, acillerde sık kullanılan görüntüleme yöntemlerinden kontrastsız tomografilerin iyi değerlendirilmesi gerekir.

\section{Conflict of Interest}

No conflict of interest was declared by the authors.

Peer-review: Externally peer-reviewed.

\section{Author Contributions}

Concept - A.Ö.; Design - A.Ö., H.M.D., Ö.K., I.T., E.A., H.Ö.; Supervision - A.Ö., H.M.D., Ö.K., I.T., E.A., H.Ö.; Funding - A.Ö., H.M.D., Ö.K., I.T., 
E.A., H.Ö.; Materials - A.Ö., H.M.D., Ö.K., I.T., E.A., H.Ö.; Data Collection and/or Processing - A.Ö., H.M.D., Ö.K., I.T., E.A., H.Ö.; Analysis and/or Interpretation - A.Ö., H.M.D., Ö.K., I.T., E.A., H.Ö.; Literature Review A.Ö., H.M.D., Ö.K., I.T., E.A., H.Ö.; Writer - A.Ö., H.M.D., Ö.K., I.T., E.A., H.Ö.; Critical Review - A.Ö., H.M.D., Ö.K., I.T., E.A., H.Ö.

\section{Çıkar Çatışması}

Yazarlar herhangi bir çıkar çatışması bildirmemişlerdir.

Hakem değerlendirmesi: Dış bağımsız.

\section{Yazar Katkıları}

Fikir - A.Ö.; Tasarım - A.Ö., H.M.D., Ö.K., I.T., E.A., H.Ö.; Denetleme - A.Ö., H.M.D., Ö.K., I.T., E.A., H.Ö.; Kaynaklar - A.Ö., H.M.D., Ö.K., I.T., E.A., H.Ö.; Malzemeler - A.Ö., H.M.D., Ö.K., I.T., E.A., H.Ö.; Veri toplanması ve/veya işlemesi - A.Ö., H.M.D., Ö.K., I.T., E.A., H.Ö.; Analiz ve/veya yorum - A.Ö., H.M.D., Ö.K., I.T., E.A., H.Ö.; Literatür taraması - A.Ö., H.M.D., Ö.K., I.T., E.A.,
H.Ö.; Yazıyı yazan - A.Ö., H.M.D., Ö.K., İ.T., E.A., H.Ö.; Eleştirel İnceleme A.Ö., H.M.D., Ö.K., I.T., E.A., H.Ö.

\section{Kaynaklar}

1. Yeşilot N, Krespi Y. Serebral Ven Trombozu. Son Güncelleştirme: 27.12.2008 http://www.itfnoroloji.org/svh/venoztromboz.htm

2. Cumurciuc R, Crassard I, Sarov M, Valade D, Bousser MG. Headache as the only neurological sign of cerebral venous thrombosis: a series of 17 cases. J Neurol Neurosurg Psychiatry 2005; 76: 1084-7. [CrossRef]

3. Gosk-Bierska I, Wysokinski W, Brown RD Jr, Karnicki K, Grill D, Wiste H, et al. Cerebral venous sinus thrombosis: Incidence of venous thrombosis recurrence and survival. Neurology 2006; 67: 814-9. [CrossRef]

4. Allroggen $\mathrm{H}$, Abbott RJ. Cerebral venous sinus thrombosis. Postgrad Med J 2000; 76: 12-5. [CrossRef]

5. Azin H, Ashjazadeh N. Cerebral venous sinus thrombosis--clinical features, predisposing and prognostic factors. Acta Neurol Taiwan 2008; 17: 82-7.

6. Canhão P, Ferro JM, Lindgren AG, Bousser MG, Stam J, Barinagarrementeria $F$, et al. Causes and predictors of death in cerebral venous thrombosis. Stroke 2005; 36: 1720-5. [CrossRef] 